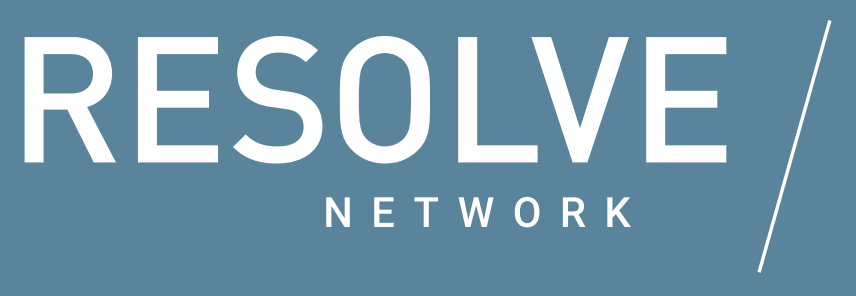

\title{
FACT/SHEET
}

LAKE CHAD BASIN RESEARCH SERIES

\section{Islam, Higher Education, and Extremism in Cameroon}

This fact sheet provides a snapshot of conclusions from RESOLVE's 2017-2019 Lake Chad Basin Research Initiative. The project assesses the role of the state, civil society, and other non-state actors in shaping the political divides over the role of religion in education and community and state responses to extremism in Chad, Nigeria, and Cameroon. Given the youthful base of Boko Haram and other violent extremist movements, policymakers have asked whether universities might either incubate or counter extremism. Discussions with stakeholders and a critical review of the literature revealed a need to test prevailing assumptions about the relationship between education, religion, and violent extremism. To learn more about the research methodology and detailed findings, please refer to the RESOLVE Research Brief by Brandon Kendhammer and Adama Ousmanou: Islam, Higher Education, and Extremism in Cameroon.
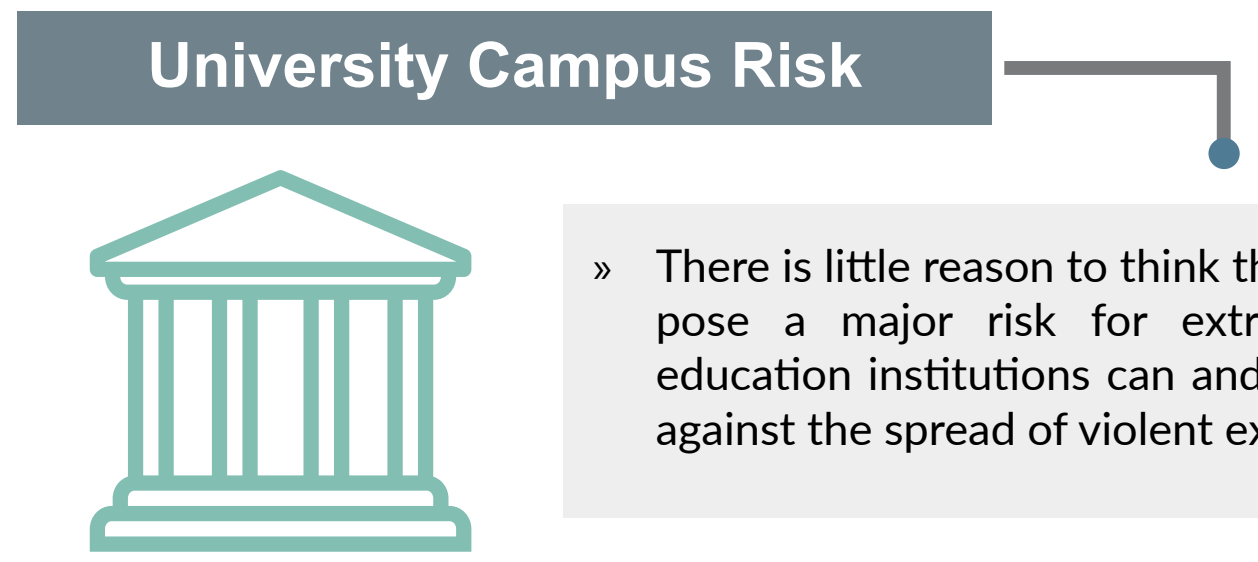

» There is little reason to think that university campuses pose a major risk for extremist activity. Higher education institutions can and do serve as a bulwark against the spread of violent extremism in the region.

\section{Perceived "Securitization"}

" The perceived "securitization" of university campuses as part of the Cameroonian war on terror has already had consequences for Muslim students, who feel surveilled, targeted, and harassed.

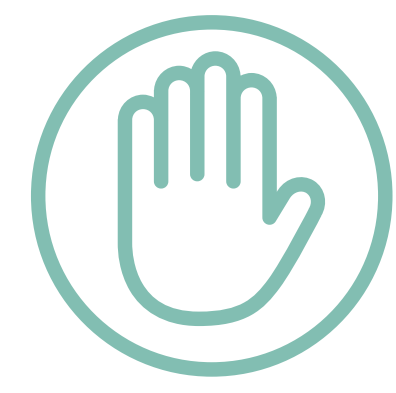




\section{Campus Opportunities}

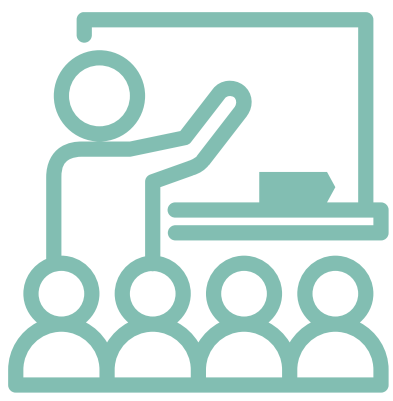

» Muslim students and faculty largely accept the "status quo" of Cameroonian state secularism; nonetheless, many see the need for universities to take on a greater role in facilitating campus religious life.

\section{State Secularism}

\section{Key Takeaways}

» Support Muslim student access to university education, and diversify the class, ethnic, and educational backgrounds of Muslim students on campus.

» Engage with religious student organizations on campus as key P/CVE partners, particularly around programs promoting nonsectarian civil engagement.

» Support additional research, specifically on the educational backgrounds of VE participants, in the Lake Chad Basin, with an emphasis on improving access to higher education for otherwise marginalized communities.

\section{RESOLVE Network}

better research.informed practice.improved policy on violent extremism. 